\title{
Perspektif Orang Tua pada Kesehatan Gigi Anak Usia Dini
}

\author{
Nuri Yuniar Wahyu Putri Abadi ${ }^{1}$, Suparno ${ }^{2}$ \\ Pascasarjana, Universitas Negeri Yogyakarta
}

\begin{abstract}
Health aspects of Early Childhood that need to be considered one of them is dental and oral health. This study involved 51 parents who had children aged 1-7 years in Lowokwaru SubDistrict, Malang City. This study aims to look at parents' perspectives on children's dental and oral health. This study used an observational method by giving questionnaires to parents. Data collection using interviews and filling out questionnaires. The results of the study show that most parents have a good enough perspective and care enough about the health of their children's teeth and mouth. However, there are still many parents who do not understand about dental caries in children. Parents who have a good enough perspective and care enough about their children's dental and oral health are not related to the parents' work factors. This research was conducted with the aim of providing an overview of parental perspectives on dental and oral health of children who can improve health services for early childhood and improve efforts for early childhood education in creating dental and oral health care programs for early childhood.
\end{abstract}

Keywords: Health, Dental, Early Childhood, Parents' Perspective

\begin{abstract}
Abstrak
Aspek kesehatan Anak Usia Dini yang perlu diperhatikan salah satunya adalah kesehatan gigi dan mulut. Penelitian ini melibatkan 51 orang tua yang memiliki anak berusia 1-7 tahun di Kecamatan Lowokwaru Kota Malang. Penelitian ini bertujuan untuk melihat perspektif orang tua terhadap kesehatan gigi dan mulut anak. Penelitian ini menggunakan metode observational dengan memberikan kuesioner kepada orang tua. Pengumpulan data dengan menggunakan wawancara dan pengisian kuisioner. Hasil penelitian menunjukkan bahwa sebagian besar orang tua memiliki perspektif cukup baik dan cukup peduli terhadap kesehatan gigi dan mulut anak. Namun, masih banyak orangtua yang tidak memahami mengenai karies gigi pada anak. Orangtua yang memiliki perspektfi cukup baik dan cukup peduli terhadap kesehatan gigi dan mulut anak tidak berhubungan dengan faktor pekerjaan orangtua. Penelitian ini dilakukan dengan tujuan memberikan gambaran mengenai perspektif orangtua terhadap kesehatan gigi dan mulut anak yang dapat meningkatkan pelayanan kesehatan untuk anak usia dini dan meningkatkan upaya pendidikan anak usia dini dalam menciptakan program pemeliharaan kesehatan gigi dan mulut untuk anak usia dini.
\end{abstract}

Kata Kunci : Kesehatan Gig; Anak Usia Dini; Perspektif Orang Tua

@Jurnal Obsesi Prodi PG-PAUD FIP UPTT 2019

$\triangle$ Corresponding author

Address : Jl. Colombo No.1, Karang Malang

ISSN 2356-1327 (Media Cetak)

Email : nuriyuniarputri@gmail.com

ISSN 2549-8959 (Media Online) 


\section{PENDAHULUAN}

Orang tua memiliki peranan penting dalam memelihara kesehatan gigi anak usia dini. Hasil sebuah studi mengatakan bahwa faktor-faktor psikososial orang tua yang telah terbukti berdampak negatif terhadap kesehatan mulut anak termasuk depresi ibu, rendahnya koherensi, pengasuhan yang memanjakan dan orang tua yang stress (Dentistry et al., 2013). Kepedulian orang tua terhadap kesehatan gigi anak dapat dilihat melalui sikap dan perhatiannya terhadap kesehatan gigi anak. Kesehatan gigi pada anak usia dini merupakan salah satu tumbuh kembang anak yang perlu diperhatikan. Sebuah studi mengatakan bahwa selama dekade terakhir penekanan telah ditempatkan pada pencegahan daripada pengobatan penyakit. Oleh karena itu penting untuk menyadari bahwa pencegahan penyakit gigi memainkan peran penting dalam perawatan kesehatan pasien secara keseluruhan (Ferretti \& Dent, 1982). Kerusakan gigi yang terjadi pada anak dapat menjadi salah satu penyebab terganggunya pertumbuhan gigi anak pada usia selanjutnya (Oktarina, Tumaji, \& Roosihermiatie, 2016). Perawatan gigi preventif harus dimulai sejak awal masa bayi, selama tahun pertama kehidupan anak untuk memastikan hasil yang sukses (Shivaprakash et al, 2009). Perhatian utama pada kesehatan gigi adalah kerusakan pada gigi-geligi primer. Karies anak usia dini, gigi busuk pada anak di bawah usia 6 tahun, adalah penyakit anak multi-faktorial dengan penentu sosialbudaya dan sosial ekonomi (Naidu, Nunn, \& Forde, 2012). Karies gigi merupakan masalah kesehatan gigi yang cukup tinggi dialami di Indonesia dengan prevalensi lebih dari $80 \%$ (Fatimatuzzahro, Prasetya, \& Amilia, 2016). Karies gigi terbentuk karena ada sisa makanan yang menempel pada gigi, yang pada akhirnya menyebabkan pengapuran gigi (Widayati, 2014). Masalah karies gigi pada anak usia dini membawa dampak yang cukup berbahaya yaitu gigi menjadi keropos, berlubang, bahkan patah sehingga membuat anak mengalami kehilangan daya kunyah dan mengganggu pencernaan (Widayati, 2014). Selain itu karies gigi dapat menyebabkan timbulnya rasa sakit pada gigi sehingga akan mengganggu penyerapan makanan dan memperngaruhi pertumbuhan anak hingga hilangnya waktu bermain anak karena sakit gigi (Fatimatuzzahro et al., 2016). Pada anak usia dini gigi yang tumbuh merupakan gigi susu yang akan lepas dan berganti dengan gigi yang baru. Namun dalam hal ini, menjaga kesehatan gigi sedini mungkin adalah hal yang dapat menjadi pembiasaan bagi anak hingga dewasa. Kesehatan gigi anak masih menjadi tanggungjawab dan perhatian orang tua, artinya anak masih bergantung kepada orang tua dalam menjaga dan merawat kesehatan giginya. Perilaku anak dalam menjaga kesehatan gigi biasanya ditunjukkan dengan cara menyikat gigi secara teratur. Namun terkadang hal tersebut tidak berbanding lurus dengan pola makan yang dijalani oleh anak. Anak usia dini masih sangat menggemari makanan dan minuman yang mengandung banyak gula. Kebiasaan anak yang mengkonsumsi makanan dan minuman yang banyak mengandung gula belum diimbangi dengan perawatan gigi yang baik dan benar. Karies gigi telah dianggap sebagai komponen penting dari beban penyakit mulut global. Fasilitas kesehatan dan penyuluhan pendidikan kesehatan gigi sudah dilakukan, namun pengetahuan masyarakat mengenai karies gigi masih rendah (Widayati, 2014).

Dampak yang ditimbulkan akibat karies gigi yang dialami anak-anak akan menghambat perkembangan anak sehingga 
akan menurunkan tingkat kecerdasan anak, yang secara jangka panjang akan berdampak pada kualitas hidup masyarakat (Widayati, 2014). Peningkatan kesehatan gigi dan mulut harus dimulai sedini mungkin, karena pada balita dan anak-anak prasekolah merupakan faktor yang sangat penting untuk pengaturan pertumbuhan gigi lebih lanjut. Selain itu, ini juga memengaruhi kemampuan anak untuk berbicara dan penguasaannya (Gigi, Bramantoro, Prabandari, Ismail, \& Tedjosasongko, 2015). Persepsi dan pengetahuan orang tua terhadap kesehatan gigi anak mempengaruhi sikap dan tindakan orang tua dalam menjaga kesehatan gigi anak serta menentukan status kesehatan gigi anak. Sebagai orang tua perlu mengajarkan kepada anak bagaimana cara menggosok gigi yang baik dan benar, kapan waktu yang tepat untuk menggosok gigi, dan rutin membawa anak untuk memeriksa status kesehatan giginya. Pengaruh tingkat keluarga ini dimediasi terutama melalui orang tua dan pengasuh dengan siapa anak-anak prasekolah menghabiskan sebagian besar waktu mereka (Naidu et al., 2012). Walaupun gigi yang tumbuh pada anak usia 1-7 tahun merupakan gigi susu, namun anak harus belajar menjaga dan merawat kesehatan gigi sedini mungkin. Beberapa faktor yang mempengaruhi status kesehatan gigi seseorang diantaranya adalah keturunan, lingkungan, perilaku, serta pelayanan kesehatan (Oktarina et al., 2016). Keterlambatan dalam perawatan gigi menciptakan sumbatan karena masalah gigi menjadi lebih rumit dan lebih mahal untuk dirawat (Clemencia \& Cynthia, 2002).

Menjaga kesehatan anak termasuk kesehatan gigi dan mulut anak merupakan salah satu tingkat pencapaian perkembangan anak usia 5-6 tahun. Dalam Peraturan Menteri Pendidikan dan
Kebudayaan mengenai pelaksanaan Pendidikan Anak Usia Dini (PAUD) disebutkan pada beberapa tingkat pencapaian perkembangan anak yaitu menjaga kebersiha diri dan lingkungan dan melakukan kegiatan kebersihan diri. Hal tersebut berkaitan dengan perilaku anak di sekolah terkait sikap hidup sehat serta berkaitan dengan program-program sekolah yang mendukung perilaku anak yang mencerminkan hidup sehat dan mengajarkan cara hidup sehat (PAUD, 2014). Kesehatan gigi anak merupakan salah satu faktor pendukung keberhasilan tumbuh kembang anak. Kesehatan gigi anak usia dini memengaruhi kesejahteraan, keterampilan, kompetensinya, dan memengaruhi hasil kesehatan secara keseluruhan. Selain faktor kepedulian orang tua, kinerja sekolah juga memiliki hubungan dengan kesehatan mulut anakanak yang baik. Kesehatan mulut anakanak yang buruk menyebabkan jutaan hari sekolah yang terlewatkan setiap tahun (Fisher-owens et al., 2007). Hal tersebut dapat mempengaruhi aspek perkembangan anak yang lainnya. Salah satu hal yang penting bahwa anak pada usia prasekolah memiliki komunikasi yang baik dengan guru di sekolah. Dalam membangun komunikasi yang efektif antara guru dan murid, sebagai komunikator yang baik, guru harus memiliki karakteristik yang dapat menarik perhatian para muridnya (Prasanti \& Fitriani, 2018). Hal tersebut juga berlaku ketika guru berkomunikasi dengan anak dalam menyampaikan hal-hal yang terkait dengan kebersihan gigi dan mulut anak, seperti mengajarkan cara menggosok gigi yang benar, menyampaikan kepada anak bahwa menjaga kesehatan gigi itu sangat penting, dan juga menyampaikan kepada orang tua bahwa sekolah telah mengajarkan cara menjaga kesehatan gigi kepada anak agar dapat digunakan sebagai kegiatan yang 
dilakukan di rumah. Sehingga orang tua perlu bekerja sama dengan sekolah dalam meningkatkan perspektif dan kepedulian terhadap kesehatan gigi anak. Dalam penelitian ini, disajikan data faktual mengenai gambaran perspektif dan kepedulian orang tua terhadap kesehatan gigi anak yang dapat digunakan sebagai landasan atau acuan dalam menentukan solusi untuk meningkatkan perspektif dan kepedulian orang tua bersama layanan pendidikan anak usia dini terhadap kesehatan gigi anak.

\section{METODOLOGI}

Metode penelitian ini adalah deskriptif dengan menggunakan metode survei deskriptif. Survei deskriptif merupakan suatu metode dalam penelitian yang dilakukan untuk mendeskripsikan atau menjelaskan secara rinci suatu fenomena yang terjadi di masyarakat. Populasi dalam penelitian ini adalah orang tua yang memiliki anak berusia 1-7 tahun yang berjumlah 51 orang. Sedangkan sampel yang digunakan dalam penelitian ini adalah total sampling artinya seluruh sampel dijadikan sebagai sampel penelitian.

Teknik pengumpulan data terdiri dari menyiapkan instrument yang digunakan dalam pemeriksaan kesehatan gigi anak dan kuesioner yang diisi oleh orangtua. Untuk mendapatkan data perilaku dan kepedulian orang tua terhadap kesehatan gigi anak seperti kebiasaan memeriksa gigi ke dokter, usia pengenalan gosok gigi, frekuensi anak menggosok gigi dalam satu hari, waktu anak ketika menggosok gigi, mengajarkan cara menggosok gigi yang benar, pengetahuan orang tua tentang gigi karies dilakukan melalui pengisian kuisioner oleh orang tua.

Penelitian ini dilakukan dengan tujuan untuk melihat bagaimana perspektif orang tua yang bekerja di luar rumah dan orang tua yang di rumah terhadap kesehatan gigi anak.

\section{HASIL DAN PEMBAHASAN}

\section{Hasil Penelitian}

Berdasarkan hasil pengolahan kuisioner ditampilkan pada tabel 1 bahwa sebanyak $56,9 \%$ orang tua berada di rumah. Dari 51 responden, sebanyak $64,7 \%$ orang tua memiliki anak berjenis kelamin laki-laki. Sebanyak $76,47 \%$ orang tua mengajarkan anak menggosok gigi pada usia 1-2 tahun. Dari 51 responden, $68,6 \%$ orang tua mendampingi anak untuk menggosok gigi 2 kali dalam sehari. Pengetahuan orang tua terhadap waktu yang tepat bagi anak untuk menggosok gigi masih minim berdasarkan data yang didapat, sebanyak $52,94 \%$ orang tua mengajarkan anak menggosok gigi pada waktu mandi pagi dan sore. Padahal yang paling tepat adalah menyikat gigi setiap kali selesai makan (sarapan, makan siang, dan makan malam) (Depkes, 2008).

\section{Tabel 1. Pekerjaan Orang tua}

\begin{tabular}{|l|c|c|}
\hline Pekerjaan & $\mathbf{N}$ & $\mathbf{\%}$ \\
\hline Guru & 11 & 21,58 \\
\hline Dosen & 4 & 7,84 \\
\hline Wiraswasta & 4 & 7,84 \\
\hline Pedagang & 3 & 5,88 \\
\hline $\begin{array}{l}\text { Ibu Rumah } \\
\text { Tangga }\end{array}$ & 29 & 56,86 \\
\hline Jumlah & 51 & 100 \\
\hline
\end{tabular}

Tabel 1 menunjukkan kriteria responden berdasarkan pekerjaannya. Mayoritas responden adalah ibu rumah tangga. Pekerjaan orang tua bukan menjadi satu-satunya pengaruh kesehatan gigi dan mulut anak. 
Tabel 2 Jenis Kelamin Anak

\begin{tabular}{|l|c|c|}
\hline $\begin{array}{c}\text { Jenis } \\
\text { Kelamin }\end{array}$ & n & \% \\
\hline Perempuan & 18 & 35,3 \\
\hline Laki-laki & 33 & 64,7 \\
\hline Jumlah & 51 & 100 \\
\hline
\end{tabular}

Tabel 3 Usia Anak Mulai Menggosok

Gigi

\begin{tabular}{|l|c|c|}
\hline \multicolumn{1}{|c|}{ Usia } & $\mathbf{N}$ & $\mathbf{\%}$ \\
\hline 1-2 tahun & 39 & 76,47 \\
\hline 2-3 tahun & 10 & 19,61 \\
\hline 3-4 tahun & 2 & 3,92 \\
\hline 4-5 tahun & 0 & 0 \\
\hline 5-6 tahun & 0 & 0 \\
\hline 6-7 tahun & 0 & 0 \\
\hline Jumlah & 51 & 100 \\
\hline
\end{tabular}

Tabel 4 Frekuensi Anak Menggosok

Gigi

\begin{tabular}{|l|c|c|}
\hline $\begin{array}{c}\text { Frekuensi } \\
\text { Waktu }\end{array}$ & N & \% \\
\hline 1 kali sehari & 13 & $25,5 \%$ \\
\hline 2 kali sehari & 35 & $68,6 \%$ \\
\hline $\begin{array}{l}\text { Lebih dari } 2 \\
\text { kali sehari }\end{array}$ & 2 & $3,9 \%$ \\
\hline $\begin{array}{l}\text { Kurang dari } \\
1 \text { kali } \\
\text { sehari/jarang }\end{array}$ & 1 & $2 \%$ \\
\hline Jumlah & 51 & 100 \\
\hline
\end{tabular}

Tabel 5 Waktu Anak Menggosok Gigi

\begin{tabular}{|l|c|c|}
\hline \multicolumn{1}{|c|}{$\begin{array}{l}\text { Waktu Menggosok } \\
\text { Gigi }\end{array}$} & N & \% \\
\hline $\begin{array}{l}\text { Ketika Mandi Pagi } \\
\text { dan Sore }\end{array}$ & 27 & 52,94 \\
\hline $\begin{array}{l}\text { Setelah Makan dan } \\
\text { Sebelum Tidur }\end{array}$ & 11 & 21,57 \\
\hline $\begin{array}{l}\text { Pagi dan sebelum } \\
\text { tidur }\end{array}$ & 13 & 25,49 \\
\hline Jumlah & 51 & 100 \\
\hline
\end{tabular}

Tabel 6 Pengetahuan Orang tua tentang

Tujuan dari Menggosok Gigi

\begin{tabular}{|l|c|c|}
\hline $\begin{array}{c}\text { Pengetahuan Orang } \\
\text { Tua }\end{array}$ & N & \% \\
\hline $\begin{array}{l}\text { Agar gigi tidak } \\
\text { berlubang }\end{array}$ & 28 & 54,9 \\
\hline $\begin{array}{l}\text { Agar gigi bersih dan } \\
\text { mulut wangi }\end{array}$ & 34 & 66,7 \\
\hline Agar nafas segar & 6 & 11,8 \\
\hline Agar gigi putih & 8 & 15,7 \\
\hline Jumlah & 51 & 100 \\
\hline
\end{tabular}

Tabel 7 Sikap Orang tua dalam Mencegah Gigi Karies pada Anak

\begin{tabular}{|l|c|c|}
\hline \multicolumn{1}{|c|}{ Sikap Orang tua } & N & \% \\
\hline $\begin{array}{l}\text { Rutin periksa ke dokter } \\
\text { gigi }\end{array}$ & 7 & 13,73 \\
\hline Rajin Menggosok gigi & 33 & 64,71 \\
\hline $\begin{array}{l}\text { Mengurangi makanan } \\
\text { dan minuman manis }\end{array}$ & 11 & 21,57 \\
\hline Jumlah & 51 & 100 \\
\hline
\end{tabular}

Tabel 8 Frekuensi Pemeriksaan Gigi ke Dokter Gigi

\begin{tabular}{|l|c|c|}
\hline \multicolumn{1}{|c|}{ Frekuensi } & N & \% \\
\hline 1 kali dalam 6 bulan & 7 & 13,73 \\
\hline 1 kali dalam 1 tahun & 10 & 19,61 \\
\hline 1 kali dalam 2 tahun & 20 & 39,22 \\
\hline Tidak pernah & 14 & 27,45 \\
\hline Jumlah & 51 & 100 \\
\hline
\end{tabular}

Tabel 9 Pengetahuan tentang Gigi Karies

\begin{tabular}{|l|c|c|}
\hline $\begin{array}{c}\text { Orang tua memahami } \\
\text { tentang gigi karies }\end{array}$ & $\mathbf{N}$ & $\boldsymbol{\%}$ \\
\hline Ya & 23 & 45,10 \\
\hline Tidak & 28 & 54,90 \\
\hline Jumlah & 51 & 100 \\
\hline
\end{tabular}

Disajikan pada tabel 6 bahwa sebanyak $66,7 \%$ orang tua beranggapan bahwa tujuan dari menggosok gigi adalah agar gigi bersih dan mulut wangi. Hal tersebut menandakan bahwa orang tua belum memahami tujuan dari menggosok 
gigi bagi kesehatan gigi anak. Kepedulian orang tua terhadap pentingnya melakukan kunjungan ke dokter gigi juga masih rendah. Disajikan pada tabel 7 dan 8 bahwa orang tua lebih banyak memilih rajin menggosok gigi dan mengurangi makanan serta minuman manis daripada melakukan kunjungan ke dokter gigi. Sebanyak $13,73 \%$ saja orang tua yang rutin memeriksakan gigi anak kepada dokter gigi. Sebuah studi yang relevan juga menunjukkan bahwa anak TK yang karies dengan tingkat perilaku orang tua dalam pemeriksaan gigi dan mulut anak kurang lebih banyak dibandingkan dengan anak yang karies dengan tingkat perilaku orang tua dalam pemeriksaan gigi dan mulut anak baik (Widayati, 2014).

Berdasarkan hasil penelitian, dapat disimpulkan bahwa sebanyak 56,86\% orang tua yang berada di rumah tidak semuanya memahami bahwa anak dianjurkan untuk menggosok gigi sebayak 3 kali sehari yaitu setelah makan pagi, makan siang, dan makan malam. Hal tersebut dibuktikan pada tabel 4 dan 5 yaitu hanya $3,9 \%$ orang tua yang mengajarkan anak untuk menggosok gigi sebanyak lebih dari 2 kali sehari dan hanya sebanyak $21,57 \%$ orang tua yang membiasakan anak menggosok gigi pada saat setelah makan dan sebelum tidur.

Sedangkan untuk pengetahuan orang tua terhadap gangguan kesehatan gigi pada anak yaitu karies gigi, dari 56,86\% orang tua yang berada di rumah sebanyak $13,73 \%$ orang tua yang melakukan tindakan kunjungan ke dokter gigi dalam upaya mencegah gigi karies sedangkan mayoritas sebanyak $64,71 \%$ orang tua melakukan upaya pencegahan karies gigi dengan cara membiasakan anak untuk rajin menggosok gigi dan sisanya sebanyak $21,57 \%$ orang tua melakukan upaya mengurangi memberi makanan dan minuman manis kepada anak untuk mencegah karies gigi anak selain itu tidur dengan botol yang berisi cairan manis, durasi penggunaan botol, menyikat gigi yang tidak mencukupi, dan sering mengonsumsi karbohidrat adalah faktor risiko karies anak usia dini (Fisher-owens et al., 2007). Penggunaan botol untuk minum tidak dianjurkan pada anak usia lebih dari 2 tahun. Pada anak usia 0-2 tahun seharusnya masih mendapatkan ASI eksklusif dari ibunya, akan tetapi sebuah penelitian mengatakan bahwa sebanyak 72 ibu dari 120 ibu tidak memberikan asi eksklusif untuk anaknya (Lestari, 2017) sehingga cara yang dapat dilakukan dalam memberikan nutrisi kepada anaknya menggunakan botol.

Dari $56,86 \%$ orang tua yang berada di rumah, sebanyak $19,61 \%$ melakukan kunjungan pemeriksaan gigi anak kepada dokter gigi sebanyak 1 kali dalam 1 tahun. Mayoritas sebanyak 39,22\% orang tua melakukan kunjungan ke dokter gigi 1 kali dalam 2 tahun. Dari 51 orang tua mayoritas sebanyak $54,90 \%$ tidak memahami tentang karies gigi pada anak. Sehingga dapat disimpulkan bahwa baim orang tua yang bekerja maupun orang tua yang di rumah dalam penelitian yang telah dilakukan memiliki perspektif yang cukup baik terhadap kesehatan gigi anak dilihat melalui data yang didapat meliputi kesadaran orang tua dalam mengajarkan anak menggosok gigi, upaya-upaya yang dilakukan orang tua dalam menjaga kesehatan gigi anak, membiasakan anak menggosok gigi sejak usia 1-2 tahun. Hal tersebut sesuai dengan rekomendasi American Academy of Pediatric Dentistry (AAPD) bahwa bayi harus berkonsultasi dengan dokter gigi dalam waktu 6 bulan untuk mendapatkan gigi pertama mereka atau pada ulang tahun pertama mereka (Alshehri, 2015). Akan tetapi orang tua belum cukup baik dalam memahami karies gigi pada anak. Hal tersebut dibuktikan 
melalui data hasil penelitian yang menunjukkan bahwa mayoritas orang tua mengakui tidak memahami tentang karies gigi pada anak dan masih banyak orang tua yang membiasakan anak menggosok gigi dengan tujuan agar gigi putih dan bersih.

\section{Pembahasan}

Pada dasarnya orang tua harus memiliki pengetahuan dan kesadaran yang baik dalam menjaga kesehatan gigi pad anak. Anak-anak yang orang tuanya memiliki pengetahuan orang tua yang rendah tentang kebersihan mulut yang benar memiliki peningkatan jumlah karies gigi dibandingkan anak-anak yang orang tuanya memiliki pengetahuan lebih (Mahat \& Bowen, 2017). Hubungan antara perilaku kesehatan mulut orang tua dan status kesehatan mulut dan perilaku anakanak prasekolah mereka, dan menemukan hubungan yang signifikan antara frekuensi orang tua menyikat gigi dan frekuensi anak menyikat gigi (Mahat \& Bowen, 2017). Selain itu efikasi diri orang tua yang lebih tinggi dikaitkan dengan lebih sering menyikat gigi (oleh orang tua dan anak) dan lebih sering mengunjungi dokter gigi (Mahat \& Bowen, 2017).

\section{Menurut American Dental} Association dan American Academy of Pediatrics, setiap anak harus dibawa ke dokter gigi sebelum berusia satu tahun atau pada saat erupsi gigi sulung pertama (Abbas et al., 2017). Penyakit mulut pada anak-anak lebih tinggi di antara kelompok populasi miskin dan kurang beruntung (Mahmoud, Kowash, Hussein, Hassan, \& Al Halabi, 2017). Sejumlah faktor yang terkait dengan anak-anak, ibu atau dokter gigi dapat menyebabkan kolaborasi yang buruk selama perawatan gigi (Fazli \& Reza, 2015). Menentukan kesehatan mulut anak-anak sangat dipengaruhi oleh ibu mereka; sebagai pengasuh utama.
Kurangnya pengetahuan sebagian dikombinasikan dengan perilaku dan keyakinan yang mengarah pada praktik pemberian makan yang buruk, pemeliharaan kebersihan mulut yang buruk, dan kegagalan untuk mencari perawatan gigi profesional tampaknya menempatkan anak tertentu pada risiko lebih tinggi terkena karies daripada anakanak lain dengan perawatan lebih (Mahmoud et al., 2017).

Banyak faktor yang menjadi pengaruh perhatian orang tua terhadap kesehatan anak. Beberapa faktor orang tua lain mungkin termasuk tingkat pendidikan ibu, pekerjaannya, usia, pengetahuan saat ini, sikap, dan perilaku terhadap kesehatan. Faktor-faktor ini menentukan keputusan yang diambil ibu tentang kesehatan anaknya (Mahmoud et al., 2017). Sebuah studi menunjukkan bahwa kecerdasan emosional ibu berkorelasi positif dengan perilaku anak dalam pengaturan gigi dan dapat menjadi prediktor perilaku anak. Ini berarti anak-anak yang memiliki ibu yang lebih cerdas secara emosional, memiliki perilaku yang lebih adaptif selama perawatan (Fazli \& Reza, 2015). Sehingga dapat disimpulkan bahwa banyak faktor yang mempengaruhi kesehatan gigi anak, akan tetapi perspektif orang tua terhadap kesehatan gigi anak penting untuk meningkatkan kepedulian orang tua terhadap kesehatan gigi anak.

Peningkatan pengetahuan orang tua mengenai kesehatan mulut melalui intervensi seperti wawancara motivasi dan bimbingan antisipatif memiliki potensi untuk meningkatkan kesehatan mulut anak melalui perubahan perilaku (Manton, 2018). Untuk menentukan langkah yang dapat diambil dalam upaya meningkatkan perspektif dan kepedulian orang tua terhadap kesehatan gigi anak, hal yang perlu dilakukan antara lain mengidentifikasi peran yang sangat 
diperlukan orang tua tentang perawatan kesehatan untuk anak-anak mereka, menilai pengetahuan dan sikap orang tua tentang kesehatan mulut bayi, memberi edukasi kepada orang tua tentang kebersihan mulut adalah langkah penting selanjutnya karena orang tua adalah pemberi perawatan primer (Alshehri, 2015). Edukasi untuk orang tua mengenai pentingnya menjaga kesheatan gigi dan mulut anak dapat dilakukan oleh layanan pendidikan anak usia dini dengan cara mengadakan sosialisasi kesehatan anak.

Upaya-upaya sosialisasi yang dapat dilakukan oleh layanan pendidikan anak usia dini kepada orang tua dalam meningkatkan perspektif dan kepedulian terhadap kesehatan gigi dan gangguan kesehatan gigi pada anak dapat dilakukan melalui banyak hal, salah satunya memanfaatkan media sosial sebagai wadah edukasi yang tentunya harus diberikan oleh pihak yang berwenang seperti dokter gigi ataupun perawat gigi.

\section{KESIMPULAN}

Perspektif orang tua terhadap kesehatan gigi anak mempengaruhi sikap dan perilaku orang tua dalam menjaga kesehatan gigi anak. Orang tua yang memiliki perspektif baik terhadap kesehatan gigi anak berbanding lurus dengan kesehatan gigi anak. Pemeriksaan kesehatan gigi pada anak dan pemberian penyuluhan kepada orang tua tentang cara menjaga kesehatan gigi anak perlu ditingkatkan agar semakin baik kesehatan gigi anak-anak Indonesia

\section{UCAPAN TERIMA KASIH}

Peneliti mengucapkan terimakasih kepada kedua orang tua dan kedua pembimbing penelitian yang telah memberikan semangat dan dukungan kepada penulis sampai penelitian ini selesai. Ucapan terima kasih juga disampaikan kepada tim editor Jurnal Obsesi yang telah memberikan saran, kritik, dan rekomendasi untuk perbaikan artikel ini.

\section{DAFTAR PUSTAKA}

Alshehri, A. (2015). Infant oral health care knowledge and awareness among parents in Abha city of Aseer Region, Saudi Arabia. The Saudi Journal for Dental Research, 6(2), 98-101. https://doi.org/10.1016/j.sjdr.2015.01. 001

Clemencia, M., \& Cynthia, R. (2002). Relationship between children' $\mathrm{s}$ dental needs and dental care utilization: United States , 19881994.

Dentistry, C., Duijster, D., Centrum, A., Amsterdam, T., Centrum, A., Amsterdam, T., ... Amsterdam, T. (2013). The role of family functioning in childhood dental caries, (August 2018).

https://doi.org/10.1111/cdoe.12079

Depkes. (2008). Psikososial. Www.Depkes.Go.Id.

Fatimatuzzahro, N., Prasetya, R. C., \& Amilia, W. (2016). Gambaran Perilaku Kesehatan Gigi Anak Sekolah Dasar di Desa Bangalsari Kabupaten Bantaeng. Jurnal IKESMA, 12(2), 85.

Fazli, M., \& Reza, M. (2015). Parents ' s Anxiety on Children Cooperation at Dental Visit. Procedia - Social and Behavioral Sciences, 205(May), 117121. https://doi.org/10.1016/j.sbspro.2015. 09.035

Ferretti, G. A., \& Dent, M. (1982). Maintaining Oral Health. Symposium on Oral Health, 29(3), 653-668. https://doi.org/10.1016/S00313955(16)34185-2

Fisher-owens, S. A., Fisher-owens, S. A., Gansky, S. A., Platt, L. J., Weintraub, 
J. A., Bramlett, M. D., \& Newacheck, P. W. (2007). Influences on Children 's Oral Health : A Conceptual Model Influences on Children ' $\mathrm{s}$ Oral Health: A Conceptual Model The online version of this article, along with updated information and services , is located on the World Wide Web at:, (October). https://doi.org/10.1542/peds.20063084

Gigi, M. K., Bramantoro, T., Prabandari, Y. S., Ismail, D., \& Tedjosasongko, U. (2015). The development of early childhood caries impact on quality of life - Indonesia instrument as assessment instrument of dental caries impact on quality of life of children aged 3-5 years based on Indonesian community characteristics, 197(56), 197-203.

https://doi.org/10.20473/j.djmkg.v48.i 4.p197-203

Lestari, R. R. (2017). Jurnal obsesi, 1(2), 97-104.

Mahat, G., \& Bowen, F. (2017). Parental Knowledge about Urban Preschool Children 's Oral Health Risk, 43(1).

Mahmoud, N., Kowash, M., Hussein, I., Hassan, A., \& Al Halabi, M. (2017). Oral health knowledge, attitude, and practices of Sharjah mothers of preschool children, United Arab Emirates. Journal of International Society of Preventive and Community Dentistry. https://doi.org/10.4103/jispcd.JISPCD _310_17

Manton, D. J. (2018). EClinicalMedicine Child Dental Caries - A Global Problem of Inequality. EClinicalMedicine, 1, 3-4. https://doi.org/10.1016/j.eclinm.2018. 06.006

Naidu, R., Nunn, J., \& Forde, M. (2012). Oral healthcare of preschool children in Trinidad: a qualitative study of parents and caregivers. BMC Oral Health, 12(1), https://doi.org/10.1186/1472-6831-
$12-27$

Oktarina, Tumaji, \& Roosihermiatie, B. (2016). Korelasi Faktor Ibu Dengan Status Kesehatan Gigi Dan Mulut Taman Kanak-Kanak di Kelurahan Kemayoran Kecamatan Krembangan, Kota Surabaya. Pusat Penelitian Dan Pengembangan Humaniora Dan Manajemen Kesehatan, 19(17), 226235.

PAUD, S. N. (2014). PERMENDIKBUD No. 137 Th. 2014 .

Prasanti, D., \& Fitriani, D. R. (2018). Jurnal Obsesi : Jurnal Pendidikan Anak Usia Dini Building Effective Communication Between Teachers and Early Children In PAUD Institutions, 2(2), 259-266. https://doi.org/10.31004/obsesi.v2i2.9 6

Widayati, N. (2014). Factors associated with dental caries in children aged 4-6 years old. Jurnal Berkala Epidemiologi, 196. https://doi.org/10.20473/jbe.V2I2201 4.196-205 